Revista Multidisciplinar do Nordeste Mineiro, v.2 2019/02

ISSN 2178-6925

\title{
ESTUDO DE VIABILIDADE ECONÔMICA PARA IMPLANTAÇÃO DE UM CONSÓRCIO PÚBLICO INTERMUNICIPAL DE ATERRO SANITÁRIO NO MUNICÍPIO DE TEÓFILO OTONI
}

Ruth Lopes Negreiros

Engenheira Florestal, formada pela Universidade Federal Rural do Rio de Janeiro MSc. Em Ciência da Educação Superior, Especialista em Doenças de Plantas pela Universidade Federal de Lavras, professora no Centro Universitário DoctumEmail: rlnegreiros@yahoo.com.br

Pedro Henrique Gonçalves dos Santos.

Engenheiro Civil, formado pelo Centro Universitário Unidoctum de Teófilo Otoni. Email: Resumo

pedroxxlider@hotmail.com

No Brasil tem se discutido sobre o aumento na geração de resíduos sólidos e a importância de sua destinação final adequada. Sabe-se que quando negligenciada a gestão dos resíduos sólidos, podeocasionar impactos de ordem econômica, ambiental e social. Estudos apontam que grande parte dos municípios brasileirosnão apresenta um plano de gestão integrada para os resíduos sólidos, alegando não ter recursossuficientes.Nesse cenárioa situação tende a se tornar cada vez mais prejudicial para população,tendendo a uma estrutura insustentável.Portanto,o presente estudo objetivou analisar a viabilidade de implantação de um consórcio público intermunicipal de aterro sanitário no município de Teófilo Otoni, situado no estadode Minas Gerais, e que atenda municípios no raio de $60 \mathrm{~km}$ (Campanário, Itambacuri, Frei Gaspar, Ouro Verde e Poté). Para tanto buscou-se a quantidade populacional atendida pela coleta de resíduos sólidos juntamente com a produção média de resíduos per capita, utilizando informações da base de dados do Sistema Nacional de Informações sobre o Saneamento Básico. No intuito de obter os custos de implantação, estimou-se a população e a produção de resíduos sólidos de todos os municípios até o ano de 2038, seguidamente calculou-se a produção média diária de resíduos sólidos. Com a produção média de resíduos foi possível dimensionar o aterro. A quantidade média de resíduos sólidos encontrada foi de 255ton/dia, para esta quantidade diária dimensionou-se um aterro com área de aproximadamente 19,2 hectares com uma vida útil de 20 anos. Com base nas dimensões do aterro calculou-se os custos relacionadosà pré-implantação e implantação do aterro sanitário com os valores fornecidos pela Associação Brasileira de Empresas de Tratamento de Resíduos e Efluentes, no qual estimou o custo total no valor $\mathrm{R} \$ 15.497 .734,65$. Conforme a análise de viabilidade econômica estabelecida pela relação Benefício/Custo, o resultado obtido foi igual 1. Portanto conclui-se que é inviável a implantação de um consórcio intermunicipal de aterro sanitário para atender os municípios de Teófilo Otoni, Itambacuri, Poté, Ouro Verde e Frei Gaspar, somente com os recursos advindos de coleta de taxa de resíduos sólidos.

Palavras-chave: Aterro Sanitário.Custo. Gestão de Resíduos Sólidos

\section{Abstract}


In Brazil, there has been a discussion about the increase in solid waste generation and the importance of its adequate last destination. It is known that when the management of solid waste is neglected, it can cause economic, environmental and social impacts. Studies indicate that most municipalities do not present an integrated management plan for solid waste, claiming they do not have sufficient resources. In this scenario the situation tends to become increasingly harmful to the population, tending to an unsustainable structure. The present study aimed at analyzing the feasibility of implementing an intermunicipal public landfill consortium in the municipality of TeófiloOtoni, located in the state of Minas Gerais, which serves municipalities within a radius of $60 \mathrm{~km}$ (Campanário, Itambacuri, Frei Gaspar, Ouro Verde and Poté). In order to do so, we sought the population quantity served by the collection of solid waste together with the average production of waste per capita, using information from the database of the National Information System on Basic Sanitation. In order to obtain the implantation costs, the population and solid waste production of all municipalities was estimated up to the year 2038, then the average daily production of solid was calculated. With the average production of waste, it was possible to size the landfill. The average amount of solid waste found was 255 tons / day, for this daily amount a landfill with an area ofapproximately 19.2 hectares with a useful life of 20 years was designed. Based on the landfill dimensions, the costs related to the pre-implantation and implantation of the landfill were calculated with the values provided by the Brazilian Association of Waste and Wastewater Treatment Companies, in which the total cost was estimated in the amount $R \$ 15,497$ .734.65. According to the economic feasibility analysis established by the Profit / Cost ratio, the result obtained was equal to 1 . Therefore it is concluded that it is impracticable to implement an inter-municipal consortium of landfills to serve the municipalities of TeófiloOtoni, Itambacuri ,Poté, Ouro Verde and Frei Gaspar, only with the resources derived from solid waste collection.

Keywords: Landfill. Cost. Solid Waste Management.

\section{Introdução}

No Brasil grandes partes dos municípios não dispõem de um método de tratamento integrado para os resíduos sólidos. O Instituto Brasileiro de Geografia eEstatística, estima que sómetade das cidades apresenta plano de gestão integrada para atender esta demanda (IBGE, 2017). Conforme estudos da Associação Brasileira das Empresas de Limpezas Públicas e Resíduos Especiais, o resultado dessa inércia ocasiona impactos ambientais relevantes, como o despejo irregular de milhões de toneladas de lixo por ano (ABRELPE, 2011).Talnível atinge a qualidade de vida da população, expondo o cidadão ao risco de doenças, confirmando que o gerenciamento dos resíduos sólidos urbanos (RSU) não pode ser negligenciado.

Nesse cenário aregião sudeste se destaca por ser responsável por mais da metade dos resíduos gerados no Brasil, no entanto, os estados da região propõem esforços para reduzir esta quantidade (SANTOS; SOUZA, 2017).Contudoo governo de Minas Gerais estimula a efetivação dos princípios de desenvolvimento 
sustentável, através de programas em parceria com o setor privado (FUNDAÇÃO ESTADUAL DO MEIO AMBIENTE, 2016).

A população urbana de Minas Gerais com acesso a sistemas de coleta de RSU passou de 19,2\% em 2003 para 45,92\% em dezembro de 2008, beneficiando cerca de 7,5 milhões de pessoas. Segundo a Gerência de Saneamento Ambiental da Fundação Estadual do Meio Ambiente(FEAM), Minas Gerais tem 462 lixões, 241 aterros controlados, 49 municípios atendidos com aterros sanitários e 95 usinas de triagem e compostagem (FEAM,2016).

O município de Teófilo Otoni situado na região nordeste do estado de Minas Gerais, possui $81,44 \%$ dos seus habitantes com acesso ao sistema de coleta de lixo domiciliar conforme dados do Sistema Nacional de Informações sobre Saneamento (SNIS, 2017). Mas, a destinação dos RSU em vazadouro a céu aberto prejudica o meio ambiente, propiciando poluição do ar, do solo, dos recursos hídricos, logo atingindo a qualidade de vida da população.Oestado atual tende a tornarmais prejudicial, pois Teófilo Otoni trata-se de ummunicípio polo emergente, ocasionando crescimento populacional,gerando um adensamento urbano e,consequentemente, aumentando a produção de resíduos, sem que haja uma disposição final adequada, levando a uma estrutura insustentável.Todavia, os dados do cenário econômico, comprovam que grande parte dos municípios não tem condições financeiras de tratar adequadamente os RSU,nesse cenário encontra-se os municípios: de Teófilo Otoni, Campanário, Poté, Ouro Verde, Itambacuri e Frei Gaspar. Entretanto a lei que institui a política nacional de resíduos sólidos a 12.305/10 determina que, desdeagosto de 2010, os municípios deveriam substituir os lixões por um sistema de disposição final de resíduos sólidos adequada. Para auxiliar os municípios menos favorecidos, a leiconsidera a possibilidadedeum gerenciamento consorciado.

O consórcio intermunicipal de aterro sanitário surge como uma ferramenta de gestão integrada dos municípios cooperados, para dedicarem esforços em suprir insuficiência de recursos, no intuito de proporcionar o tratamento adequado doRSU. Nesse sentido a pesquisa teve como objetivo analisar a viabilidade econômica de um consórcio intermunicipal de aterro sanitário na cidade de Teófilo Otoni que atenda cidades no raio de $60 \mathrm{~km}$.Para atingir o objetivo proposto no presente estudo, foi necessário elaborar o levantamento legal, o levantamento técnico e levantamento financeiro do aterro sanitário.

A pesquisa é documental, de natureza quantitativa e nível descritivo e consiste nos seguintes procedimentos: fundamentação bibliográficaem livros, 
monografias, revistas e artigos científicos relacionados ao tema proposto. Levantamento de informações por meio de documentos públicosna base de dados virtuais (ABETRE, IBGE, SNIR e SNIS). A planilha de custos foi elaborada conforme cotações práticas e custos unitários de publicações da Associação Brasileira de Empresas de Tratamento de Resíduos (ABETRE). Com auxílio do Excel, efetuou-se cálculos de extrapolação populacional, projeção de geração de resíduos, vida útil do aterro, dimensões do aterro sanitárioe o custo final para a implantação. Para analisar a viabilidade, foiutilizadaa relação de custo/benefício.

Nesse contexto o trabalho tende avalorizar o espaço acadêmico, como fonte de pesquisa para trabalhos futuros relacionados ao tema, no meio social a fim de discutir o socioambiental dentro do cenário atual do despejo irregular de resíduos sólidos, no âmbito técnico no fato de analisar a viabilidade do projeto.

\section{REFERENCIAL TEÓRICO}

\subsection{Definição de resíduos sólidos}

Para Matos,Gomes e Ribeiro (2015) os seres humanos sempre produziram resíduos sólidos devido suas atividades rotineiras desde a mudança para vida nômade por volta de 10 mil anos a.C.Mas, com a migração dos povos, a definição de resíduos sólidos é relativa, influenciada pela condição socioeconômica e a cultura local em determinada época. (TÉDDE et al., 2014). Contudo Carloset al., (2012)define "resíduos sólidos como os restos oriundos das atividades diárias do homem, sendo domésticas ou industriais". Já Borba et al., (2016) caracteriza resíduos sólidos como produtos ou subprodutos seguidamente descartados após atividade humana, assemelhandocom a definição proposta peloConselho Nacional do Meio Ambiente(Conama)que entende resíduos sólidos, como aqueles em estados sólidos e semi sólidos, que derivam de atividades oriundas deindustrias, serviçosdomésticos e hospitalares, varrição de logradouro, incluindo o lodo derivados dos sistemas de tratamento de água. Devido ao volume ea variedade, os resíduos sólidos são classificados e divididos em grupos, para melhor gerencia-los(CONAMA, 2004).

\subsection{Classificação e caracterização dos resíduos sólidos}

Quando se propõe classificar e caracterizar os tipos de resíduos sólidos é importante conhecer a origem do material e ainda conhecer as suas condições no tocante aos aspectos químicos, físicos e biológicos, essas informações serão úteis 
para o seu gerenciamento adequado, além de permitir avaliar os possíveis impactos ambientais gerados pelo contato com a natureza.

No intuito de caracterizar os resíduos quanto a sua composição, a NBR 10.004/2014 classifica os resíduos de acordo com o risco proporcionado ao meio ambiente, sendo os resíduos de classe I considerados como perigosos, uma vez que apresenta características reativas, tóxicas e inflamáveis, os resíduos classe II Asão denominados não inertes,devido não serem considerados perigosos e nem como inertes, podendo apresentar propriedades de biodegradabilidade, combustibilidade ou solubilidade, já os resíduos classe II B denominados inertes, são aqueles que não sofrem transformação em sua composição durante um determinado tempo. (ASSOCIAÇÃO BRASILEIRA DE NORMAS TÉCNICAS, 2004)

Neste contexto, outra forma de classificação dos resíduos sólidos surge com o desenvolvimento do setor da construção civil. No intuito de melhor gerenciar o grande volume de resíduos sólidos oriundos dos canteiros de obra, o CONAMA estabelece normas que melhor direcionasse o gerenciamento dos resíduos sólidos provenientes desta atividade, com a finalidade de minimizar os impactos ambientais. Para tanto o CONAMA (2004) estabelece asdiretrizes, critérios e procedimentos para a gestão dos resíduos da construção civil.

Entretanto para aumentar a qualidade dos processos gerenciais o CONAMA

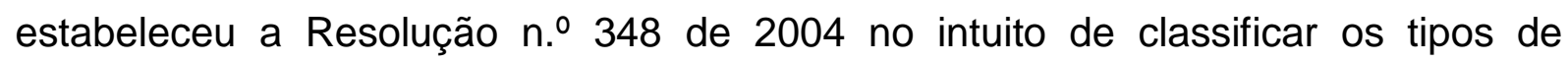
resíduos. Nesta classificação os resíduos reutilizáveis foram denominados Classe $A$ que são aqueles provenientes de atividades de demolição, reformas ou provenientes de desperdício dos processos construtivos, exemplos: resíduos de alvenaria, resíduos de concretos, resíduos de peças cerâmicas entre outros. A norma classifica também os resíduos recicláveis denominados Classe $B$, que podem ser reutilizados para outras destinações como: plásticos, papéis e papelões, os resíduos denominados Classe $\mathrm{C}$, são aqueles não foram desenvolvidas tecnologias economicamente viáveis para sua recuperação ou reciclagem, podendo citar: poliuretano, sacos de cimentos, isopordentre outros. Já os resíduos denominados Classe D são resíduos oriundos do processo de construção ou demolição como: latas, materiais de amianto, sobras de materiais de pintura.(CONAMA, 2004)

Avaliando importante conhecer a origem dos resíduos para propor mecanismos de controle ambiental, surge em 02/08/2010a lei $n^{\circ} 12.305 / 2010$, no artigo 13 classifica os resíduos quanto a origem, ondedenominaresíduos sólidos 
urbanos ( $\underline{\mathrm{RSU}}$ ), como conjunto formado de resíduos domiciliares e de limpeza urbana,em que os municípios tem a obrigação de gerenciar de forma adequada.

\subsection{Legislação e diretrizes sobre os resíduos sólidos}

A lei 6938/1981 dispõe de diretrizesque regemPolítica Nacional do Meio Ambiente. É uma ferramenta que consolida e efetividade do artigo 225 da constituição em defesa do meio ambiente. Portanto tem a finalidade de regularizar a utilização dos recursos naturais no intuito de preservar a natureza e promover o equilíbrio do ecossistema (MIRANDA, 2015).

A sensibilização da importância de proteger o ecossistema, tanto quanto a criação de mecanismos de preservação, tem destaque inicial com a publicação do artigo 225 da Constituição Federal no qual: outorga ao poder público e a sociedade a responsabilidade de zelar pelo meio ambiente, pronunciando que todo tem o dever de preservá-Io. (CONSTITUIÇÃO FEDERAL, 1988).

O poder público no intuito de ser mais efetivo na preservação dos recursos naturais promulgou em a Lei 9.605/98, denominada leis de crimes ambientais

Para obter um controle sobre os crimes ambientais, o governo federal hierarquiza a responsabilidade do bom usodo meio ambiente, atribuindo aos municípios o seu papel de fiscalizador.Portanto, cada município tem dever de elaborar seu respectivo plano municipal de saneamento básico (PMSB). O plano municipal de saneamento básico, entre outras atribuições surge como uma ferramenta de planejamento e controle dos resíduos sólidos.

Considerando a importância do tratamento adequado dos resíduos sólidos, o governo federal promulgou em 2010 como ferramenta de planejamento, a Lei da Política Nacional dos Resíduos Sólidos (PNRS), tornando a primeira legislação federal a regular o tema dos resíduos sólidos no país. Segundo Pereira, Lira e Rodrigues (2013)a Lei n. 12.305/2010, que instituiu a PNRS, apresenta diretrizes para o desenvolvimento sustentável e destacou o importante serviço social prestado pelos catadores na redução do volume de lixo gerado no Brasil.Para o bom funcionamento da lei, criou-se mecanismos de monitoramento com a finalidade de obter maior controle sobre os seus resultados.

Como ferramenta de monitoramento da PNRS criou-seo Sistema Nacional de Informações sobre a Gestão dos Resíduos Sólidos (SINIR) com o objetivo de guiar as ações necessárias ao cumprimento da lei. (ALMEIDA, 2015, p.14) 
Para tanto no intuito de propor ações efetivas, a PNRS definiu no Art. 9ำ que no gerenciamento de resíduos sólidos deve adotar a seguinte ordem de prioridade: não geração, redução, reutilização,reciclagem, tratamento e disposição final ambientalmente adequada. Posteriormente no seu art. 10 o Programa Nacional de Resíduos Sólidos atribui aos municípios à competência da gestão integrada dos resíduos gerados em seus respectivos territórios.

O processo de gestão pode incluir a separação dos resíduos na fonte, implantação do sistema de coleta seletiva, para direcionar parte dos resíduos para programas de reciclagem e compostagem (MEDEIROS e ALBERTO, 2011).

\subsection{Gestão de resíduos sólidos urbanos}

Conforme Conti e Martins (2015) o sistema capitalista, influenciadiretamente a forma de gerenciar os resíduos sólidos, uma vez que o uso demasiado dos recursos naturais produz um aumento significativo na geração de resíduos sólidos. Segundo Ribeiro (2017) a revolução industrial foi o fator que alavancou a geração de resíduos, devido o modelo de produção das indústrias em larga escala.

Neste contexto "o aumento da geração per capita deresíduos sólidos está diretamente relacionada ao consumo exagerado, rápido crescimento populacional e seu adensamento espacial"(LUIZ et al.,2011, p.171). Considerando que o fator principal para a geração de resíduos em um país, seja o crescimento econômico, deve levar em consideração os hábitos da população. Uma comparação da cultura de consumo americana em relação à japonesa, embora ambos tenham alto poder de consumo, os americanos produzem praticamente o dobro de resíduos per capita que os japoneses (GODEKE; HARB; SGANDERLA, 2012). Ao longo dos anos verifica-se a relação entre o desenvolvimento econômico e o aumento da geração de resíduos sólidos, evidenciando necessidade de promover uma gestão efetiva.

A gestão de resíduos sólidos segundoMedeiros e Alberto (2011) é fundamental e não pode ser negligenciada,os municípios que não possui uma gestão sustentável podem sofrer impactos negativos, como a poluição hídrica, degradação do solo e a proliferação de vetores. No Brasil, como em outros países em desenvolvimento, outros malefícios somam-se à questão ambiental, ocasionados por deficiências na gestão dos resíduos sólidos urbanos (GODEKE; HARB; SGANDERLA, 2012, p.1701). Dentro do panorama atual os resíduos sólidos ganham notoriedade quanto aos seus impactos no meio ambiente, havendo a necessidade de discutir modelos de gestão sustentáveis. 
Para Farinas (2006) o modelo de gestão eficiente deve partir dos seguintes princípios: redução dos resíduos gerados pela população, reutilização dos materiais descartados e a reciclagem dos materiais úteis para a indústria, este método é denominado como o processo dos 3 R's: reduzir, reutilizar e reciclar.Nesse contexto a Agenda 21, no tema sustentabilidade da ênfase aos princípios dos 3 R's e do poluidor-pagador, que institui a cada um a questão da responsabilidade pela geração de resíduos e seus impactos ambientais(ROBERTO; RISSO; LUIZ, 2012).

Para verificar os resultados de um modelo de gestão eficiente é essencial analisar a redução dos impactos ambientais. Assim a Política Nacional de Resíduos Sólidos (PNRS) propõe diretrizes, além de estabelecer metas de adequação, necessária para cumprimento dalegislação (GOMES; VENTURA; RODRIGUES, 2014).

A Agenda 21 no contexto de resíduos sólidos destacou os impactos causados pela sua disposiçãoirregular, tornando como meta a disposição dos resíduos de forma adequada(ROBERTO; RISSO; LUIZ, 2012).

No processo de disposição, Medeiros e Alberto(2011) afirmam que, a receita geral para uma gestão adequada é aparentemente simples: a coleta abrangente (que atinja mais de $90 \%$ da população), com frequência adequada (três ou mais vezes por semana); a limpeza pública que mantenha os logradouros em condições satisfatórias de uso; os resíduos depositados corretamente em um aterro sanitário.

\subsection{Considerações sobre os os componentes do sistema de aterro sanitário}

Segundo Araújo et al., (2017) o aterro sanitário é um método de disposição final de resíduos sólidos urbanos, que visa proteger 0 meio ambiente consequentemente a saúde pública, garantindo a segurança e o bem-estar da população. Nesse contexto, o Plano Nacional dos Resíduos Sólidos destacou a efetividade do aterro sanitário, estipulou uma meta para o fechamento dos lixões desde o ano de 2014, induzindo o poder público a implantação de aterros sanitários (ALMEIDA, 2015). Para que o aterro sanitário seja efetivo, o projeto deve ser fundamentado em técnicas de engenharia e normas operacionais específicas, no intuito de destinar os resíduos na menor área possível, reduzindo os impactos ambientais. Em relação à efetividade do aterro sanitário,Hamada (2003) consolida que o projeto do aterro sanitário, tem como objetivo ser um sistema ecologicamente adequado para a disposição final dos resíduos, portanto deve ser executado conforme procedimentos técnicos, que vão desde a escolha do local, quanto aos mecanismos para reduzir os impactos ambientais causados ao meio ambiente, 
através de procedimentos técnicos operacionais, como: drenagem, cobertura diária e o tratamento de efluentes líquidos e gasosos (HAMADA, 2003).

Considerando o porte do aterro, verifica-se a viabilidade técnico-econômica do empreendimento, considerando a possibilidade de aderir um modelo de consórcio intermunicipal, sobretudo quando o município não possuir recursos financeiros suficientes para sua implementação. De acordo com Hamada (2003), essa avaliação é a premissa para estabelecer diretrizes para a implantação do sistema. Toda via torna-se necessário avaliar constantemente a efetividade das etapaspréoperacionais propostas pelo projeto, a fim de reduzir custos desnecessários.

\subsubsection{Critérios para a escolha do local de implantação do aterro sanitário}

Segundo McBean et al; (1995) a escolha do local de implantação é um processo complexo considerando os princípios exigidos pelas normas vigentes, como: minimização de riscos para a população, capacidade da área ser de baixo impactos ambientais, maximização dos recursos operacionais e consequentemente minimizar os custos aos operadores do sistema. Dentro de um panorama técnico (HAMADA, 2005) aborda, os principais fatores que devem ser avaliados na escolha da área de implantação do aterro sanitário são: a logística; a extensão da área; as condições do solo, topografia, hidrologia de águas superficiais, condições geológicas,hidrogeológicas, condições climatológicas, distância do meio urbano e o potencial de recuperação da área degradada. No entanto é necessário verificar também os aspectos sociais e econômicos.Com base nessas informações, existem vários métodos para definir o local. Uma vez definidaaárea em que será alocado o aterro sanitário, é necessário considerar o isolamento da área, com a finalidade de evitar 0 acesso de animais domésticos. O cercamento deve priorizar a sustentabilidade, o custo e o menor impacto visual possível (HAMADA, 2005).

O local medido para disposição dos resíduos é apenas um componente do sistema, pois o aterro sanitário deve conter infraestrutura, vias de acesso, método de aterramento, células de aterramento, formato de aterramento, drenagem superficial, cobertura diária, sistemas de contenção, drenagem do chorume, tratamento do chorume, drenagem de gases e poços de monitoramento (HAMADA, 2005).

A infraestrutura do aterro sanitário está relacionada ao seu porte, e pode variar conforme a demanda solicitada, mas, deve conter no mínimo, guarita de entrada, áreas administrativas cobertas, almoxarifado, tratores, veículos de transporte e espaço para o trânsito e estacionamento de veículos (HAMADA, 2005). 
Além de estabelecer rotas de acesso externo ao aterro, internamente devem ser definidas vias principais que permitam o trânsito, sob quaisquer condições climáticas, para as células de aterramento. Vias principais são complementadas por acessos secundários às áreas de descarga. Aterros de grande porte, com declives acentuados, recomenda-se a pavimentação de vias principais (HAMADA, 2005).

\subsubsection{Classificação do aterro sanitário}

Após a escolha do local deve-se determinar o método para a operação do aterro. Para Guimarães (2000) os principais fatores considerados para determinar o método são as características físicas e geográficas da área. ConformeBatista (2005) as técnicas de operação podem ser definidas quanto ascaracterísticas físicas do aterro que podem ser definidas comoaterro de superfície e aterro em depressões.

Os métodos operacionais são definidos a partir dos aspectos topográficos do terreno, da localização do lençol freático. Podemos dividi-los em três modelos operacionais sendo: método da trincheira, método da rampa e método da área.

O método da trincheira é utilizado em áreas de topografia plana e suave. Fundamenta-se na abertura de trincheiras no solo, onde o lixo é disposto no fundo, compactado e depois recoberto com solo (BATISTA, 2005). Logo o método da rampa é empregado em áreas planas onde o solo natural oferece boas condições para ser escavado e utilizado como material de cobertura. É um método vantajoso em relação aos demais, pois modera o transporte de material de cobertura de fora do sistema. Mas, deve ser analisada a profundidade do lençol freático (BATISTA, 2005). Observa-se que existem aterros depressões que são os executados em locais de baixo valor comercial sendo na maioria das vezes utilizados clandestinamente (BATISTA, 2005).

\subsubsection{Método de aterramento}

O método utilizado para aterramento deve ser escolhido em função da quantidade de material disponível para a cobertura, e pelo espaço dispostos pelo aterro, pois o volume da cobertura influencia na vida útil do aterro (HAMADA, 2005).

\subsubsection{Células de aterramento}

São módulos de áreas previamente medidas, com a finalidade de manter o funcionamento do sistema, quanto à taxa de ocupação, servindo também como uma 
importante ferramenta para se obter um maior controle administrativo quanto aos recursos existentes, sendo necessária avaliação contínua(HAMADA, 2005).

\subsubsection{Drenagem superficial}

O aterro deve conter um sistema de drenagem superficial, através de declives projetados em relação aos índices pluviométricos, com a função de drenar as águas pluviais que escoam superficialmente, pois podem interferir diretamente na produção de chorume (HAMADA, 2005).

Ométodo de cobertura diária deve seguir padrões técnicos com base no volume total a ser coberto, gerando uma porcentagem fixa, no intuito de controlar o volume e consequentemente alcançar a vida útil planejada(HAMADA, 2005).

\subsubsection{Sistemas de contenção}

Para evitar possível contaminação do lençol freático o solo do aterro sanitário deve ser impermeabilizado com geomembranas, também conhecidas como geossintéticas, especialmente o PEAD (polietileno de alta densidade, esse sistema e denominado liners. Além de baixa permeabilidade, deve ter a função de escoar ligeiramente o líquido do aterro através de declives superiores a 1\%(HAMADA, 2005).

\subsubsection{Drenagem de chorume}

Segundo HAMADA (2005) uma vez impermeabilizada as bases do aterro, o chorume produzido pelo os resíduos escoam até os drenos laterais implantados na base dos taludes, esse dimensionamento deve ser preciso para evitar o afloramento de chorume nos períodos de chuvas intensas.Em relação ao chorume e importante que se aplique um manejo adequado e posteriormente um tratamento.

O layout deve apresentar todos os componentes da estrutura do aterro, inclusive os poços de monitoramentopara as águas subterrâneas (HAMADA, 2005).

\subsection{Processo de dimensionamento do aterro sanitário}

O dimensionamento do porte do aterro é fundamental para mensurar os custos de implantação e operação. As características físicas do aterro estão relacionadas ao seu porte, assim como os seus componentes operacionais. 0 dimensionamento doaterro depende de três fatores principais, população, média de geração de resíduos per capita e vida útil do aterro sanitário. 
Segundo Hamada (2003), a primeira etapa do projeto constitui na coleta e tratamento de dados relativos ao crescimento populacional.Existem diversos métodos para estimar o crescimento populacional, onde os parâmetros são obtidos a partir de dados conhecidos. O método aritmético possui notoriedade sendo relativamente simples se comparados aos outros métodos, mostrando-se efetivo para projeções populacionais. Esse método implica uma taxa de crescimento constante com base em dados históricos(KIRCHNER, 2007).Matematicamente pode ser demonstrada com a seguinte formula:

$\mathrm{dp} / \mathrm{dt}=\mathrm{Ka}(1)$

Onde:

$d p / d t$ representa a variação da população $(P)$ por unidade de tempo (t), e Ka é uma constante.

Considerando que P1 é a população do penúltimo censo (ano t1) e P2, a população do último censo (ano t2), temse:

$P=P_{2}+k_{a}\left(T-T_{2}\right)(2)$

Onde:

$\mathrm{P}=$ Projeção da População

$\mathrm{P} 1$ = população no ano 1

$\mathrm{P} 2$ = população no ano 2

$\mathrm{t} 1$ = ano 1 de referência

t2 $=$ ano 2 de referência

$\mathrm{Ka}=$ Taxa de crescimento anual

Sobretudo a coleta de dados precisa, influencia diretamente na qualidade final do projeto, portanto deve ser extraída de documentos ou base de dados virtuais de institutos de pesquisas.No Brasil, o IBGE é a fonte de referência para pesquisas relacionadas à população e o SNIS é a base de dados para estudos relacionados aos resíduos sólidos.

A quantidade média de resíduos gerados na área urbana deve ser sempre que possível obtida a partir de medições periódicas efetuadas pela própria prestadora de serviço de limpeza urbana (HAMADA, 2003). No Brasil os dados referentes aos resíduos sólidos são disponibilizados através do sistema nacional de informações sobre o saneamento, onde os gestores e prestadores de serviço devemfornecer anualmente os dados referentes ao manejo de resíduos sólidos (MINISTÉRIO DAS CIDADES, 2015).Toda via caso não existam registros, devem ser considerados um método estimativo com pesagens em balanças rodoviárias 
(HAMADA, 2003). Portanto considerando a fonte das informações segura para 0 estudo, deve-se buscar aquantidade de resíduos per capita,junta a projeção populacional anual seguidamente estima-se o volume total de resíduos gerados diariamente (RODRIGUES, 2017).Portantoesta relaçãopode ser descrita pela seguinteequação:

$\mathrm{Tr}=\mathrm{Gr}{ }^{*}$ pop. urb (3)

Onde:

$\operatorname{Tr}=$ Total de resíduos

$\mathrm{Gr}$ = geração per capita de resíduos sólidos urbanos

De posse da média de resíduos gerados por dia, o dimensionamento da área total do aterro, pode ser obtido seguindo o método deBatista (2005) no qual:

Porcentagem de ocupação do resíduo compactado (Prc):

$\operatorname{PrC}=(100 \% * \mathrm{Hr})(4)$

$\mathrm{Ht}$

Onde:

$\mathrm{Hr}=$ Altura da camada de resíduo

$\mathrm{Ht}=$ Altura total da célula

Onde:

$\mathrm{Ht}=\mathrm{Hr}+\mathrm{Hc}(5)$

Onde:

$\mathrm{Hr}=$ Altura da camada de resíduo

$\mathrm{Hc}=$ Altura da camada de cobertura

Volume de resíduo na descarga (Vrd):

$\operatorname{Vrd}=\underline{\operatorname{Mr}\left(\mathrm{m}^{3}\right)}$

$\delta$ (dia)

Onde:

$\delta=$ Massa específica $\left(t / \mathrm{m}^{3}\right)$

Volume de resíduo compactado ( $\mathrm{Vrc})$ :

$\operatorname{Vrc}\left(\mathrm{m}^{3} / \mathrm{dia}\right)=\operatorname{Vrd}+\operatorname{Rv}(7)$

Onde:

$R v=$ Redução volumétrica $=1 / 4$

Volume diário do aterro $(\mathrm{Vt})$ :

$\mathrm{Vt}\left(\mathrm{m}^{3} / \mathrm{dia}\right)=\underline{100 \% * \operatorname{Vrc}(8)}$

$70 \%$

Área do aterro $(\mathrm{A})$ : 
$\mathrm{A}\left(\mathrm{m}^{2} / \mathrm{dia}\right)=\underline{\mathrm{Vt}}$

$\mathrm{H}$

Área total do aterro $(\mathrm{At})$ :

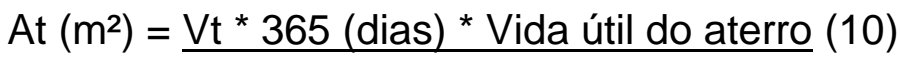

$\mathrm{Ht}$

Área final do aterro $(\mathrm{Af})$ :

$A f=A t * 1,2(11)$

Com base no resultado na equação 11 , estabelece as dimensões do aterro.

Avaliando o alto custo da implantação do sistema, por se tratar de um empreendimento físico a longo prazo, o poder público pode aderir ao modelo consorciado, reduzindo gastos e ampliando a efetividade do projeto, atendendo municípios impossibilitados economicamente deimplantar o aterro sanitário.

\subsection{Análise de viabilidade pelo metódo benficio e custo}

A análise da viabilidade econômica de um sistema de aterro sanitário, quando não se tem a finalidade de obter lucro como resultado do empreendimento, tende a adentrar na perspectiva benefício/custo,podendo ser estabelecida pela razão entre o valor presente dos benefíciosdividido pelo valor presente do custo de investimento. Daí,Hortolani (2008)o resultado pode ser obtido pela equação:

$\mathrm{RBC}=\frac{P_{B}}{P_{C}}$

Onde:

RBC - Relação Benefício-Custo;

PB - Valor presente dos benefícios

PC - Valor presente dos custos.

Conforme a equação descrita Hortolani (2008) estabelece que os resultados da Relação Benefício-Custo serão analisados da seguinte forma:

Se $\mathrm{RBC}<1 \Rightarrow$ o benefício é menor do que o custo do projeto, portanto o tipo dedisposição final é inviável economicamente;

Se RBC $=1 \Rightarrow$ o benefício é igual ao custo do projeto, portanto o tipo de disposiçãofinal também é inviável economicamente; ou

Se RBC $>1 \Rightarrow$ o benefício é maior do que o custo do projeto, portanto o tipo dedisposição final é viável economicamente.

\subsection{Consórcio público intermunicpal de aterro sanitário}


Os municípios brasileiros de pequeno porte, devido à falta de recursos orçamentários não teriam condições financeiras de implantar um aterro sanitário que atenda as exigências legais (DANTAS, 2012).

Os consórcios surgem como ferramenta operacional que auxilia os municípios sem recursos suficientes para atingir objetivos em comum(DANTAS, 2012). ParaSilva (2012), o Brasil tem mais de 5.500 municípios, a maioria de pequeno porte, que certamente não conseguirá viabilizar as soluções exigidas de maneira individual.

O consórcio público intermunicipal de aterro sanitário é uma boa alternativa para gerir os resíduos sólidos urbanos (RSU), já que grande parte dos municípios não possui recurso suficiente para gerenciar os resíduos de forma adequada, conforme exige a PNRS. (DANTAS, 2017)

\section{METODOLOGIA E PROCEDIMENTOS TÉCNICOS DA PESQUISA}

\subsection{Classificação da pesquisa quanto aos fins}

É de natureza descritiva corroborandocom Mattar (2001), que descreve que para este tipo de estudo: "o pesquisador precisa saber o que pretende com a pesquisa, o que deseja medir, quando, onde e como o fará e por que deverá fazê-lo" desta forma estabelece que o processo da pesquisa seja previamente definido.

A pesquisa é quantitativa, que segundo Malhotra (2001, p.155): "procura quantificar os dados, aplicando alguma forma de análise estatística".Portanto o estudo propõe estimar a população dos municípios, a produção média diária de resíduos sólidos, as dimensões do aterro e mensurar a composição de custos necessárias para a implantação do consórcio intermunicipal de aterro sanitário que atenda cidades em um raio de $60 \mathrm{~km}$,coma finalidade de investigar a viabilidade econômica dasua implantação.

Quanto à abordagem técnicaé pesquisa aplicada, pois"estuda um problema específico e a sua aplicabilidade"(LAKATOS; MARCONI, 2003). O estudo tem finalidade de investigar, a viabilidade de implantação de um aterro sanitário de forma consorciada, para reduzir os impactos causados pela disposição final inadequada.

\subsection{Classificação da pesquisa quanto aos meios}

No intuito de investigar a viabilidade de implantação de um consórcio intermunicipal de aterro sanitário, optou-se em uma pesquisa delineada como 
documental,portanto vale-se de documentos com dados originais, que são examinados em busca de novas interpretações (HELDER, 2006).

\subsubsection{Descrição e caracterização da área em estudo}

Os municípiosde Teófilo Otoni, Poté, Itambacuri, Frei Gaspar e Ouro Verde são circunvizinhos, localizados no interior do estado de Minas Gerais,na região sul do vale do Mucuri ao nordeste da capital do estado.Possuem juntosconformea estimativa do IBGEpara o ano 2018 a população de 198.043 habitantes e área territorial de $6.622,44 \mathrm{~km}^{2}$.

\section{Figura 01- Localização dosmunicípios em estudo}

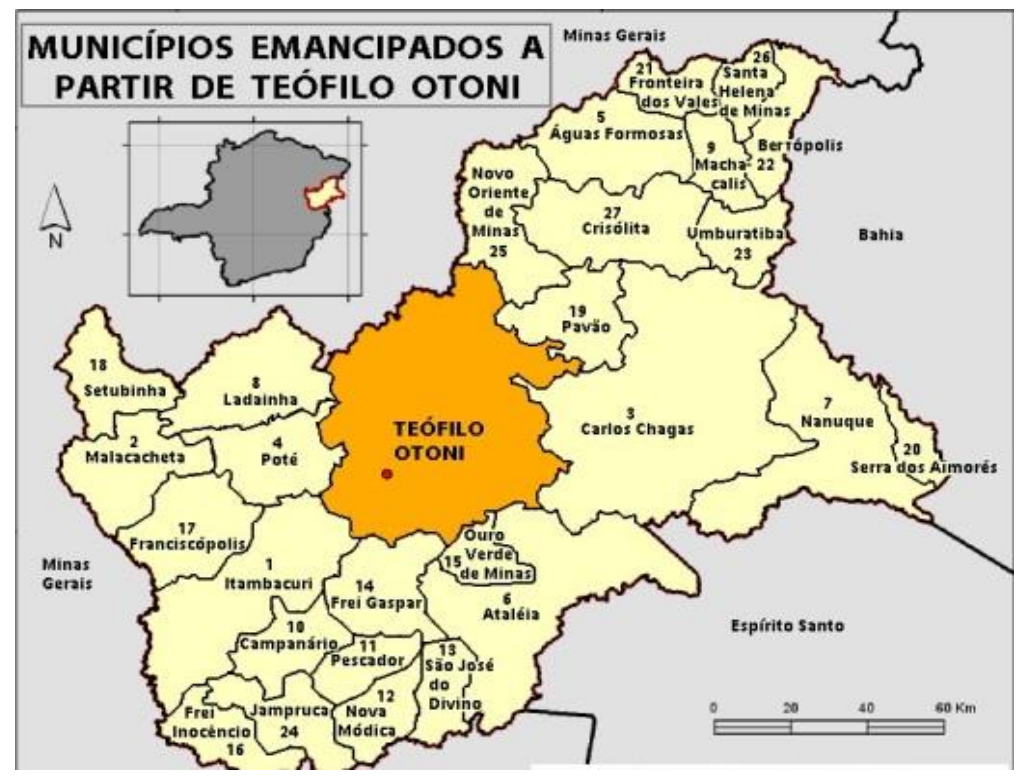

Fonte: (Conceição, 2007)

A cidade de Teófilo Otoni é a mais desenvolvida do Vale do Mucuri, possui maior extensão territorial e detém a maior população da região, conforme apresentados na Tabela 1.

Tabela1- Síntese dos dados gerais dos municípios em estudo

\begin{tabular}{|ccc|ccc|}
\hline Cidade & $\begin{array}{c}\text { Area da } \\
\text { unidade } \\
\text { territorial } \\
\text { [2017; } \mathbf{k m}^{2} \text { ] }\end{array}$ & $\begin{array}{c}\text { População } \\
\text { no último } \\
\text { censo } \\
\text { [2010] }\end{array}$ & $\begin{array}{c}\text { População } \\
\text { estimada } \\
\text { [2018] }\end{array}$ & $\begin{array}{c}\text { PIB } \\
\text { per capita } \\
\text { [2015] }\end{array}$ & $\begin{array}{c}\text { IDH } \\
\text { [2010] }\end{array}$ \\
\hline Teófilo Otoni & 3242,27 & 134745 & 140235 & $\mathrm{R} \$ 16.066,82$ & 0.701 \\
\hline Poté & 625,11 & 15667 & 16491 & $\mathrm{R} \$ 7.602,69$ & 0.624 \\
\hline Ouro Verde & 266,78 & 7800 & 8503 & $\mathrm{R} \$ 6.821,78$ & 0.595 \\
\hline Itambacuri & 1419,21 & 22809 & 23212 & $\mathrm{R} \$ 10.052,85$ & 0.634 \\
\hline Frei Gaspar & 626,67 & 5879 & 5891 & $\mathrm{R} \$ 8.396,18$ & 0.590 \\
Campanário & 442,40 & 3564 & 3711 & $\mathrm{R} \$ 10.031,03$ & 0.616 \\
\hline
\end{tabular}


Contudo Teófilo Otoni dispõe de um alto fluxo populacional, oriundo das cidades circunvizinhas, que usufruem do sistema urbano local. Toda via a cidade de Teófilo Otoni apresenta aspectos que são consideradas premissas básicas para ser sede do consórcio intermunicipal de aterro sanitário, principalmente ao se tratar do volume de geração de resíduos sólidos. Portanto comparado aos demais municípios do presente estudo (Campanário, Itambacuri, Frei Gaspar, Ouro Verde e Poté), avalia-se a cidade de Teófilo Otoni, como sede para a implantação do aterro sanitário, coma finalidade de atender os municípios em um raio de $60 \mathrm{~km}$.

\subsubsection{Coleta de dados}

Utilizou-sebases de dados virtuais, analisando artigos e monografias, parte extraída de artigos publicados em revistas científicas de confiabilidade acadêmica.

Consideraa estrutura da metodologia como bibliográfica, formulada com base em pesquisas de diversos autores. Porém, a origem dos dados para alimentar a modelagem de cálculos é de caráter documental, com base em informações dos institutos de pesquisa, prefeituras e empresas relacionadas a coleta de resíduos.

\subsection{Tratamento de dados}

O material para estudo foi analisado no intuito de detectar se a pesquisa possui embasamento teórico e científico que corrobora com o tema e extrair dados necessários para o tema proposto.

Identificada a veracidade das informações, realizou a leitura analítica e coletou-se aqueles dados de acordo com o fichamento da pesquisa, analisando todo o contexto para a interpretação das informações e uma análise crítica concisa.

\subsection{Análise e processamento de dados}

Levantou-se a estrutura teórica confirmando as informações da pesquisa.Os dadosexaminados foram processados medianteos seguintes procedimentos: fundamentação bibliográfica em livros, monografias, revistas e artigos científicos. Levantamento de informações por meio de documentos públicos na base de dados virtuais (ABETRE, IBGE, SNIR e SNIS). A planilha de custos foi elaborada conforme cotações práticas e custos unitários de publicações da Associação Brasileira de Empresas de Tratamento de resíduos (ABETRE). Com auxílio da ferramenta Excel efetuou-se os cálculos de extrapolação populacional, projeção de geração de resíduos, vida útil do aterro, dimensões do aterro sanitário e custos das etapas de 
construção, para obtenção do custo final. Para analisar a viabilidade, foi utilizada uma relação de custo/benefício.

\section{Resultados e discussão}

\subsection{Quantitativosda população e geração de resíduos sólidos urbanos}

Com base no Sistema Nacional de Informação sobre o Saneamento Básico,buscou-se dados dos municípiosreferente à população atendida pela a coleta de resíduos sólidos urbanos e a quantidade total produzidos anualmente. As informações foram extraídas do SNISe organizadas conforme a Tabela a seguir:

Tabela2 - Dados referente a população atendida pela coleta de resíduos sólidos e quantidade de resíduos sólidos urbanos coletados por ano

\begin{tabular}{|c|c|c|c|}
\hline Município & $\begin{array}{c}\text { Ano de } \\
\text { Referência }\end{array}$ & $\begin{array}{l}\text { CO050 - População urbana } \\
\text { atendida no município, } \\
\text { abrangendo o distrito- } \\
\text { sede e localidades } \\
\text { (Habitantes) }\end{array}$ & $\begin{array}{l}\text { C0119 - Quantidade } \\
\text { total de RDO e RPU } \\
\text { coletada por todos os } \\
\text { agentes (Tonelada/ano) }\end{array}$ \\
\hline Campanário & 2010 & 3564 & 975,65 \\
\hline Campanário & 2017 & 3711 & $1.015,89$ \\
\hline Frei Gaspar & 2012 & 1.911 & 288 \\
\hline Frei Gaspar & 2013 & 1.766 & $1.080,00$ \\
\hline Frei Gaspar & 2014 & 1.500 & $1.890,00$ \\
\hline Frei Gaspar & 2015 & 1.965 & $1.080,00$ \\
\hline Itambacuri & 2013 & 8.300 & $6.192,00$ \\
\hline Itambacuri & 2014 & 8.300 & $6.192,00$ \\
\hline Itambacuri & 2016 & 15.600 & 571,3 \\
\hline Ouro Verde & 2010 & 6016 & $1.646,88$ \\
\hline Ouro Verde & 2017 & 5954 & $1.629,91$ \\
\hline Poté & 2011 & 9.000 & $1.000,00$ \\
\hline Poté & 2014 & 9.791 & $4.612,80$ \\
\hline Poté & 2015 & 9.835 & $4.296,60$ \\
\hline Poté & 2016 & 9.877 & 800 \\
\hline Teófilo Otoni & 2010 & 105.000 & $52.611,00$ \\
\hline Teófilo Otoni & 2011 & 110.000 & $26.160,00$ \\
\hline Teófilo Otoni & 2012 & 110.733 & $25.400,00$ \\
\hline Teófilo Otoni & 2013 & 114.424 & $146.427,00$ \\
\hline Teófilo Otoni & 2014 & 114.832 & $82.794,00$ \\
\hline Teófilo Otoni & 2015 & 115.223 & $44.135,00$ \\
\hline Teófilo Otoni & 2016 & 115.596 & $45.000,00$ \\
\hline
\end{tabular}

Fonte: (SNIS, 2018)

Com base nos dados da Tabela 2, conheceu-se a quantidade de resíduos produzidos diariamentee per capitapor município,pelas as seguintes equações:

Quantidade de resíduos (kg/dia) = Quantidade de resíduos anual $\times 1000(13)$ 365

Quant. resíduos per capita $(\mathrm{kg} / \mathrm{dia})=$ Quantidade de resíduos $(\mathrm{kg} / \mathrm{dia})(14)$

População atendida pela coleta 
Com a base na Tabela 2 sob auxílio da ferramenta Excel, obteve-se os valores organizados na Tabela3.

\section{Tabela3- Dados referente a quantidade de resíduos sólidos produzidos por dia e a geração de resíduos per capita de cada município}

\begin{tabular}{|c|c|c|c|}
\hline Municipio & $\begin{array}{l}\text { Ano de } \\
\text { Referência }\end{array}$ & $\begin{array}{l}\text { Quantidade total } \\
\text { de RDO e RPU } \\
\text { produzidos por dia } \\
\text { (kg/dia) }\end{array}$ & $\begin{array}{l}\text { Quantidade total de } \\
\text { resíduos per capita } \\
\text { (kg/dia) }\end{array}$ \\
\hline Campanário & 2010 & $2.673,01$ & 0,75 \\
\hline Campanário & 2017 & $2.783,26$ & 0,75 \\
\hline Frei Gaspar & 2012 & 789,04 & 0,41 \\
\hline Frei Gaspar & 2013 & $2.958,90$ & 1,68 \\
\hline Frei Gaspar & 2014 & $5.178,08$ & 3,45 \\
\hline Frei Gaspar & 2015 & $2.958,90$ & 1,51 \\
\hline Itambacuri & 2013 & $16.964,38$ & 2,04 \\
\hline Itambacuri & 2014 & $16.964,38$ & 2,04 \\
\hline Itambacuri & 2016 & $1.565,21$ & 0,10 \\
\hline Ouro Verde & 2010 & $4.512,00$ & 0,75 \\
\hline Ouro Verde & 2017 & $4.465,51$ & 0,75 \\
\hline Poté & 2011 & $2.739,73$ & 0,30 \\
\hline Roté & 2014 & $12.637,81$ & 1,29 \\
\hline Poté & 2015 & $11.771,51$ & 1,20 \\
\hline Poté & 2016 & $2.191,78$ & 0,22 \\
\hline Teófilo Otoni & 2010 & $144.139,73$ & 1,37 \\
\hline Teófilo Otoni & 2011 & $71.671,23$ & 0,65 \\
\hline Teófilo Otoni & 2012 & $69.589,04$ & 0,63 \\
\hline Teófilo Otoni & 2013 & $401.169,86$ & 3,51 \\
\hline Teófilo Otoni & 2014 & $226.832,88$ & 1,98 \\
\hline Teófilo Otoni & 2015 & $120.917,81$ & 1,05 \\
\hline Teófilo Otoni & 2016 & $123.287,67$ & 1,07 \\
\hline
\end{tabular}

Fonte: (Dados da própria pesquisa, 2018

Por meio de análise rigorosa dos dados, identificou-se a falta de informações em determinados anos,que podem ser porinadimplência dos municípios quanto à falha no fornecimento de dadosou erro de processamento do sistema.Toda via valorizou-se a credibilidade do sistema, afim de utilizar os dadosexatos proposta por cada município, considerando a importância para cada município de estarem atualizados, quanto regularidade de alimentação dos dados no sistema nacional de informações sobre o saneamento básico (SNIS), sob pena de não recebimento de recursos de programas federais,sendo necessário a apresentação do documento de atestado de regularidade com o fornecimento de dados ao SNIS,emitido pelo Ministério das Cidades. (Ministério das Cidades, 2015)

Conforme dados processado na Tabela 3 verificou-se que os municípios que possuem uma maior renda, tendem a ter a maior geração de resíduos sólidos per capita.No entantoo município de Teófilo Otoni que detém a maior economia entre os municípios, apresenta divergências quando se comparado ao município de Itambacuri,como no ano 2014 em que apresentaa produção per capita inferior de $0,06 \mathrm{~kg} / \mathrm{dia} / \mathrm{hab}$. Desta maneira salienta-se que devem ser considerados na 
avaliação dos fatores de geração de resíduos sólidosos aspectos sociais, principalmente os padrões de consumo de municípios.

É possível perceber que ao decorrer dos anos por influência do desenvolvimento econômico local a geração de resíduos de sólidos per capita tende a aumentar. Nesse contexto surge a necessidade de propor mecanismos para sensibilizar os consumidores e consequentemente adequar os padrões de consumo, no intuito de diminuir o impacto causado ao meio ambiente.

Toda via considerou a produção de resíduos sólidos com base nos dados históricos disponíveise estimou a população futura até o ano de 2038 para cada município,utilizando do método aritmético supracitado no item 2.6 da pesquisa, o resultado estimado foi organizado conforme a Tabela 4.

Tabela4 - Estimativa populacional pelo método aritmético para os municípios nos próximos 20 anos

\begin{tabular}{|c|c|c|c|c|c|c|}
\hline & $\begin{array}{c}\text { TEOFILO } \\
\text { OTONI }\end{array}$ & ITAMBACURI & POTE & $\begin{array}{c}\text { FREI } \\
\text { GASPAR }\end{array}$ & CAMPANARIO & $\begin{array}{l}\text { OURO } \\
\text { VERDE }\end{array}$ \\
\hline 2017 & 117.362 & 18.033 & 10.052 & 2.001 & 3.711 & 5.954 \\
\hline 2018 & 119.128 & 20.467 & 10.228 & 2.019 & 3.732 & 5.945 \\
\hline 2019 & 120.894 & 22.900 & 10.403 & 2.037 & 3.753 & 5.936 \\
\hline 2020 & 122.660 & 25.333 & 10.579 & 2.055 & 3.774 & 5.927 \\
\hline 2021 & 124.426 & 27.767 & 10.754 & 2.073 & 3.795 & 5.919 \\
\hline 2022 & 126.192 & 30.200 & 10.929 & 2.091 & 3.816 & 5.910 \\
\hline 2023 & 127.958 & 32.633 & 11.105 & 2.109 & 3.837 & 5.901 \\
\hline 2024 & 129.724 & 35.067 & 11.280 & 2.127 & 3.858 & 5.892 \\
\hline 2025 & 131.490 & 37.500 & 11.456 & 2.145 & 3.879 & 5.883 \\
\hline 2026 & 133.256 & 39.933 & 11.631 & 2.163 & 3.900 & 5.874 \\
\hline 2027 & 135.022 & 42.367 & 11.806 & 2.181 & 3.921 & 5.865 \\
\hline 2028 & 136.788 & 44.800 & 11.982 & 2.199 & 3.942 & 5.857 \\
\hline 2029 & 138.554 & 47.233 & 12.157 & 2.217 & 3.963 & 5.848 \\
\hline 2030 & 140.320 & 49.667 & 12.333 & 2.235 & 3.984 & 5.839 \\
\hline 2031 & 142.086 & 52.100 & 12.508 & 2.253 & 4.005 & 5.830 \\
\hline 2032 & 143.852 & 54.533 & 12.683 & 2.271 & 4.026 & 5.821 \\
\hline 2033 & 145.618 & 56.967 & 12.859 & 2.289 & 4.047 & 5.812 \\
\hline 2034 & 147.384 & 59.400 & 13.034 & 2.307 & 4.068 & 5.803 \\
\hline 2035 & 149.150 & 61.833 & 13.210 & 2.325 & 4.089 & 5.795 \\
\hline 2036 & 150.916 & 64.267 & 13.385 & 2.343 & 4.110 & 5.786 \\
\hline 2037 & 152.682 & 66.700 & 13.560 & 2.361 & 4.131 & 5.777 \\
\hline 2038 & 154.448 & 69.133 & 13.736 & 2.379 & 4.152 & 5.768 \\
\hline
\end{tabular}

Portanto conforme os dados da Tabela 4foi possível representar 0 crescimento anual pelo o gráfico demonstrado na Figura 4:

Figura 2- Demonstrativo de crescimento populacional para os próximos 20 anos 


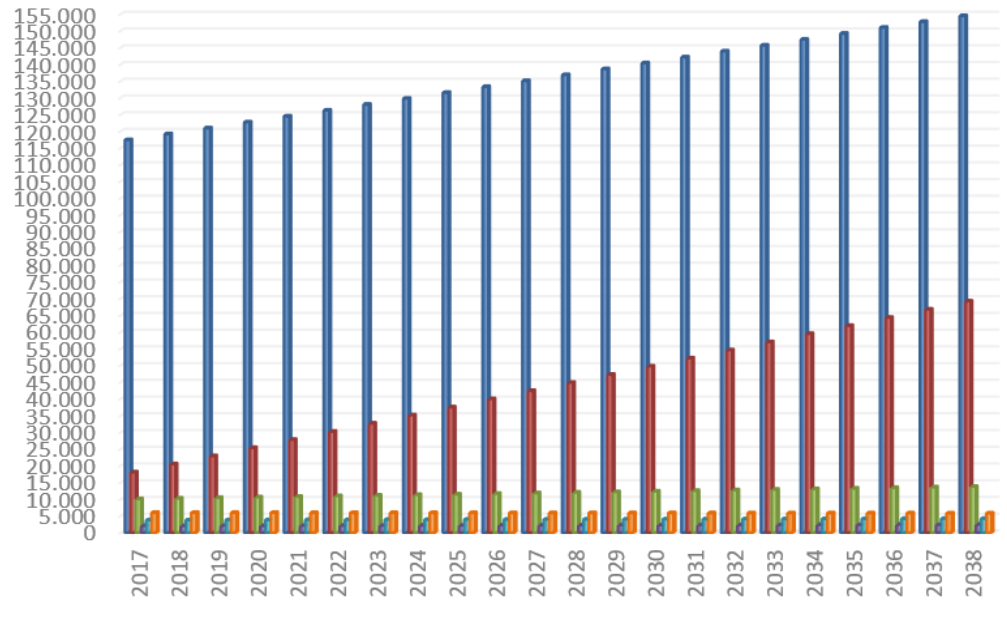

Fonte: (Dados da própria pesquisa, 2018)

\subsubsection{Projeção de estimativa de produção de resíduos sólidos no cenário 1}

No intuito de obter a estimativa de resíduos sólidos produzidos em cada município anualmente, foram projetados dois cenários. No cenário 1 , a produção de resíduos sólidos foi calculada conforme o método aritmético, em que considerou uma taxa de crescimento anual (k)acumulada progressivamente até o ano 2038. Portanto o cálculo da estimativa de produção de resíduos sólidos nos municípios para os próximos 20 anos no cenário 1 ,foi estabelecida pela seguinte equação:

Quantidade de resíduos no ano $(\mathrm{n})$ = a pop. projetada no ano $(\mathrm{n}) \mathrm{x}$ aquantidade deresíduos per capita no ano (n) (15)

A partir da equação 15 foi possível elaborar a Tabela 5.

- Estimativo de produção de resíduos sólidos pelo método aritmético (cenário 1)

\begin{tabular}{|ccccccc|} 
ANO & $\begin{array}{c}\text { TEOFILO } \\
\text { OTONI }\end{array}$ & ITAMBACURI & POTE & $\begin{array}{c}\text { FREI } \\
\text { GASPAR }\end{array}$ & CAMPANARIO & $\begin{array}{c}\text { OURO } \\
\text { VERDE }\end{array}$ \\
\hline $\mathbf{2 0 1 7}$ & $45.695,30$ & 656,13 & 814,07 & $1.078,38$ & $1.015,89$ & $1.629,91$ \\
\hline $\mathbf{2 0 1 8}$ & $46.390,84$ & 739,85 & 828,14 & $1.066,91$ & $1.021,64$ & $1.627,48$ \\
\hline $\mathbf{2 0 1 9}$ & $47.878,89$ & 822,44 & 842,20 & $1.055,47$ & $1.027,38$ & $1.625,06$ \\
\hline $\mathbf{2 0 2 0}$ & $49.404,13$ & 903,94 & 856,26 & $1.044,07$ & $1.033,13$ & $1.622,63$ \\
$\mathbf{2 0 2 1}$ & $50.967,39$ & 984,35 & 870,32 & $1.032,72$ & $1.038,88$ & $1.620,21$ \\
$\mathbf{2 0 2 2}$ & $52.569,52$ & $1.063,68$ & 884,36 & $1.021,41$ & $1.044,63$ & $1.617,78$ \\
\hline $\mathbf{2 0 2 3}$ & $54.211,39$ & $1.141,94$ & 898,41 & $1.010,15$ & $1.050,38$ & $1.615,36$ \\
\hline $\mathbf{2 0 2 4}$ & $55.893,90$ & $1.219,14$ & 912,45 & 998,95 & $1.056,13$ & $1.612,94$ \\
\hline $\mathbf{2 0 2 5}$ & $57.617,94$ & $1.295,29$ & 926,48 & 987,79 & $1.061,88$ & $1.610,51$ \\
\hline $\mathbf{2 0 2 6}$ & $59.384,45$ & $1.370,40$ & 940,51 & 976,70 & $1.067,63$ & $1.608,09$ \\
$\mathbf{2 0 2 7}$ & $61.194,37$ & $1.444,49$ & 954,54 & 965,66 & $1.073,37$ & $1.605,66$ \\
\hline $\mathbf{2 0 2 8}$ & $63.048,66$ & $1.517,56$ & 968,56 & 954,68 & $1.079,12$ & $1.603,24$ \\
\hline $\mathbf{2 0 2 9}$ & $64.948,32$ & $1.589,62$ & 982,58 & 943,76 & $1.084,87$ & $1.600,81$ \\
\hline $\mathbf{2 0 3 0}$ & $66.894,34$ & $1.660,68$ & 996,59 & 932,91 & $1.090,62$ & $1.598,39$ \\
\hline $\mathbf{2 0 3 1}$ & $68.887,75$ & $1.730,76$ & $1.010,60$ & 922,12 & $1.096,37$ & $1.595,96$ \\
\hline $\mathbf{2 0 3 2}$ & $70.929,61$ & $1.799,86$ & $1.024,60$ & 911,39 & $1.102,12$ & $1.593,54$ \\
\hline $\mathbf{2 0 3 3}$ & $73.020,99$ & $1.867,99$ & $1.038,60$ & 900,74 & $1.107,87$ & $1.591,11$ \\
\hline $\mathbf{2 0 3 4}$ & $75.162,97$ & $1.935,16$ & $1.052,59$ & 890,15 & $1.113,62$ & $1.588,69$ \\
\hline $\mathbf{2 0 3 5}$ & $77.356,68$ & $2.001,38$ & $1.066,58$ & 879,64 & $1.119,36$ & $1.586,26$ \\
\hline $\mathbf{2 0 3 6}$ & $79.603,25$ & $2.066,67$ & $1.080,56$ & 869,20 & $1.125,11$ & $1.583,84$ \\
\hline $\mathbf{2 0 3 7}$ & $81.903,85$ & $2.131,02$ & $1.094,54$ & 858,83 & $1.130,86$ & $1.581,41$ \\
\hline $\mathbf{2 0 3 8}$ & $84.259,66$ & $2.194,45$ & $1.108,52$ & 848,53 & $1.136,61$ & $1.578,99$ \\
\hline
\end{tabular}

Fonte: (Dados da própria pesquisa, 2018) 


\subsubsection{Projeção de estimativa de resíduos sólidos no cenário 2}

Para a projeção do cenário 2 ,adotou-se a média de produção de resíduos sólidos anual, com base no histórico produção per capita fornecidos pelo SNIS desconsiderando o aumento constante anual. Portanto calculou-se conforme a seguinte equação 16 :

Quantidade de resíduos no ano $(\mathrm{n})=$ a pop. projetada no ano $(\mathrm{n})$ x a média de produção de resíduossólidos (n) (16)

Tabela5 - Estimativo de produção de resíduos sólidos considerando a média de produção constante (cenário 2).

\begin{tabular}{|c|c|c|c|c|c|c|}
\hline ANO & $\begin{array}{c}\text { TEÓFILO } \\
\text { OTONI }\end{array}$ & ITAMBACURI & POTÉ & $\begin{array}{c}\text { FREI } \\
\text { GASPAR }\end{array}$ & CAMPANARIO & $\begin{array}{l}\text { OURO } \\
\text { VERDE }\end{array}$ \\
\hline 2017 & $47.977,59$ & $9.215,03$ & $2.751,84$ & 668,81 & $1.015,89$ & $1.629,91$ \\
\hline 2018 & $48.699,53$ & $10.458,47$ & $2.799,86$ & 674,83 & $1.021,64$ & $1.627,48$ \\
\hline 2019 & $49.421,47$ & $11.701,90$ & $2.847,88$ & 680,85 & $1.027,38$ & $1.625,06$ \\
\hline 2020 & $50.143,41$ & $12.945,33$ & $2.895,89$ & 686,86 & $1.033,13$ & $1.622,63$ \\
\hline 2021 & $50.865,35$ & $14.188,77$ & $2.943,91$ & 692,88 & $1.038,88$ & $1.620,21$ \\
\hline 2022 & $51.587,29$ & $15.432,20$ & $2.991,92$ & 698,90 & $1.044,63$ & $1.617,78$ \\
\hline 2023 & $52.309,23$ & $16.675,63$ & $3.039,94$ & 704,91 & $1.050,38$ & $1.615,36$ \\
\hline 2024 & $53.031,17$ & $17.919,07$ & $3.087,95$ & 710,93 & $1.056,13$ & $1.612,94$ \\
\hline 2025 & $53.753,11$ & $19.162,50$ & $3.135,97$ & 716,95 & 1.0 & $1.610,51$ \\
\hline 2026 & $54.475,05$ & $20.405,93$ & $3.183,99$ & 722,96 & $1.067,63$ & $1.608,09$ \\
\hline 2027 & $55.196,99$ & $21.649,37$ & $3.232,00$ & 728,98 & $1.073,37$ & $1.605,66$ \\
\hline 2028 & $55.918,93$ & $22.892,80$ & $3.280,02$ & 734,99 & $1.079,12$ & $1.603,24$ \\
\hline 2029 & $56.640,88$ & $24.136,23$ & $3.328,03$ & 741,01 & $1.084,87$ & $1.600,81$ \\
\hline 2030 & $57.362,82$ & $25.379,67$ & $3.376,05$ & 747,03 & $1.0 \mathrm{~s}$ & $1.598,39$ \\
\hline 2031 & $58.084,76$ & $26.623,10$ & $3.424,07$ & 753,04 & 1.09 & $1.595,96$ \\
\hline 2032 & $58.806,70$ & $27.866,53$ & $3.472,08$ & 759,06 & 12 & $1.593,54$ \\
\hline 2033 & $59.528,64$ & $29.109,97$ & $3.520,10$ & 765,08 & $1.107,87$ & $1.591,11$ \\
\hline 2034 & $60.250,58$ & $30.353,40$ & $3.568,11$ & 771,09 & $1.113,62$ & $1.588,69$ \\
\hline 2035 & $60.972,52$ & $31.596,83$ & $3.616,13$ & 777,11 & $1.119,36$ & $1.586,26$ \\
\hline 2036 & $61.694,46$ & $32.840,27$ & $3.664,14$ & 783,12 & $1.125,11$ & $1.583,84$ \\
\hline 2037 & $62.416,40$ & $34.083,70$ & $3.712,16$ & 789,14 & $1.130,86$ & $1.581,41$ \\
\hline 2038 & $63.138,34$ & $35.327,13$ & $3.760,18$ & 795,16 & $1.136,61$ & $1.578,99$ \\
\hline
\end{tabular}

\subsubsection{Síntese da relação cenário $1 \mathrm{X}$ cenário 2}

Atribuindo a atuaçãodos municípios de forma consorciada,considera-se comoprodução efetivaa soma de produção de resíduos sólidos por todos os municípios acumulado durante os 20 anos. Para obter a produçãoefetiva de resíduos sólidos, estimou-se a produção anual de cada município e projetou para 20 anos

O fruto da diferença entre os dois cenários ératificado conforme a Figura 5.

Figura 3 - Comparativo entre os métodos estimativos

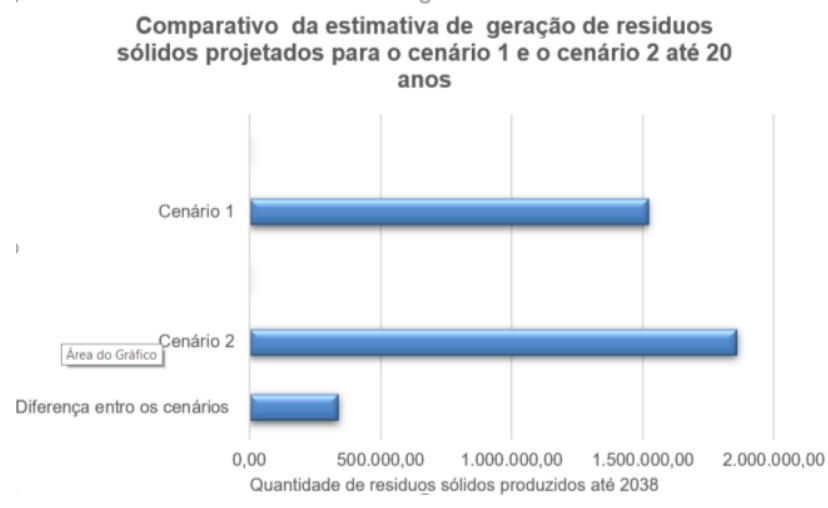

Fonte: (Dados da própria pesquisa, 2018) 
Em relação à diferença dos resultados entre os métodos adotados para a projeção de produção anual de resíduos sólidos, nota-se que ao considerar a média de produção de resíduos sólidos fixa, desconsiderando o crescimento anual acumulado durante os 20 anos, teremos uma diferença de $338.311,79$ toneladas de a mais em relação ao método aritmético, que considera a taxa de crescimento em função dos anos anteriores.

\subsection{Dimensionamento do aterro sanitário}

Para o dimensionamento do aterro sanitário de forma consorciada, o fator de maior relevânciaé a produção média diária dos resíduos sólidos dosmunicípios, portanto considera a produção média diária como:

Média de RSU gerado por dia = Total de geração de todos os municípios nos 20 anos (ton) / (365x vida útil do aterro)(17)

Para o total de resíduos produzidos nos municípios, exigido na equação17, considerou-se a produção total de1.858.950,28 toneladas obtida pela equação 15 (cenário 2), pois apresenta maior resultadose comparado ao métodoaritmético, consequentemente representa o pior cenário. Portanto a média de resíduos sólidos gerado por dia é representado pela a seguinte equação:

Onde:

Média de RSU gerado por dia $=(1.858 .950,28) /(365 \times 20)$

Média de RSU gerado por dia $=254,65$ ton (considera 255 para efeito de cálculo)

Verificou-se no presente estudo que os municípios não possuem dados disponíveis sobre o estudo gravimétricos, conforme pesquisas realizadas nas suas respectivas secretarias responsáveis pela a gestão dos resíduos sólidos locais. Nesse contexto, não é possível determinar os detalhes sobre as características dos resíduos recolhidos, como a subdivisões pelos seus respectivospotenciais recicláveis. Desta forma considera que não haverá reciclagem, nem reaproveitamento dos resíduos.

Com base na média de resíduos sólidos gerados por dia dimensionou-se ao aterro sanitário, pela equação desenvolvida por Batista (2005), supracitada no item 2.6 desta pesquisa.

Dados de Projeto:

Média diária de lixo $=255$ t/dia 
Peso específico $=0,80 \mathrm{t} / \mathrm{m} 3$

Redução volumétrica $=1: 4$ (devido a compactação)

Parâmetros de projeto:

Disposição do lixo:

Camada de lixo $=0,70 \mathrm{~m}(70 \%)$

Camada de cobertura $=0,20 \mathrm{~m}(30 \%)$

Fração do número de camadas:

5 camadas de lixo $=3,50 \mathrm{~m}$

5 camadas de cobertura $=1,50 \mathrm{~m} \rightarrow[(4 \times 0,20)+(1 \times 0,70)]$

Altura total de cada célula $=5,00 \mathrm{~m}$

Porcentagem de ocupação do resíduo compactado (Prc):

$\operatorname{Prc}=\underline{(100 \% \times 3,5)}=70 \%(18)$

5

Volume de resíduo na descarga ( $\mathrm{Vrd}$ ):

$\operatorname{Vrd}=\underline{255\left(\mathrm{~m}^{3}\right)}=318,75$ (19)

0,80 (dia)

$\delta=$ Massa específica $\left(\mathrm{t} / \mathrm{m}^{3}\right)$

Volume de resíduo compactado ( $\mathrm{Vrc})$ :

$\operatorname{Vrc}\left(\mathrm{m}^{3} / \mathrm{dia}\right)=0,25 \times 318,75=79,69 \mathrm{~m}^{3} / \mathrm{dia}(20)$

Volume diário do aterro $(\mathrm{Vt})$ :

Vt $\left(\mathrm{m}^{3} / \mathrm{dia}\right)=\underline{100 \% * 79,69 \mathrm{~m}^{3} / \mathrm{dia}}=113,84 \mathrm{~m}^{3} / \mathrm{dia} \quad$ (21)

$70 \%$

Área do aterro $(\mathrm{A})$ :

$\mathrm{A}\left(\mathrm{m}^{2} / \mathrm{dia}\right)=\underline{113,84 \mathrm{~m}^{3} / \mathrm{dia}}=22,7 \mathrm{~m}^{2} / \mathrm{dia}(22)$

5

Área total do aterro $(\mathrm{At})$ :

At $\left(\mathrm{m}^{2}\right)=\underline{113,84 \mathrm{~m}^{3} / \mathrm{dia}^{*} 365(\text { dias })}{ }^{*} 20$ anos $=166.205,36 \mathrm{~m}^{2}$ (23)

5

Área final do aterro (Af): 
O método do IBAMestabelece o fator 560 , que foi elaboradopara determinar a área mínima de um aterro sanitáriocom base em aterros que possuem as seguintes características: 20 anos de vida útil, com altura de 20 metros, taludes de um para três e taxa de ocupação 0,8 do terreno, sendo a restante área operacional (PENIDO, 2001).O fator do IBAM é estabelecido pela seguinte equação:

Área = Média de RSU gerado por dia x 560(25)

Onde:

$\mathrm{A}=255 \mathrm{t} / \mathrm{dia} \times 560=142.800,00 \mathrm{~m}^{2}(26)$

Portanto a diferença da área efetiva entre os métodos e dada da seguinte forma:

$A=166.205,36-142.800,00=23.177,70 \mathrm{~m}^{2}(27)$

Nesse sentido comparou-se o dimensionamento do aterro pelo método de Batista (2005), com o método utilizado pelo IBAM, no intuito de verificar a diferença entre os métodos de dimensionamento.Em que no método de Batista apresentou uma diferença de aproximadamente 2,34 hectares a mais do que a área mínima calculada pelo fator estabelecido pelo IBAM.

\subsection{Seleção da área para implantação de aterro sanitário}

De posse das dimensões do aterro sanitário, procurou-se identificar possíveis áreas para implantação, priorizando a logísticaem função da quantidade de resíduos a serem transportadas pelos os municípios.Portanto delimitou-se a área de abrangência dos municípios consorciados. 
Figura 4- Área de abrangência do aterro sanitário

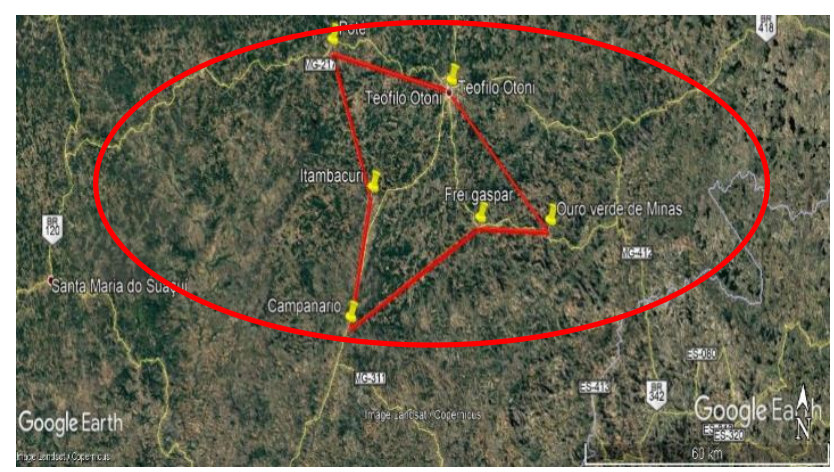

Fonte: (Google Earth, 2018)

Considerando que cada município tem a sua produção de resíduos sólidos diários, verificou-se que Teófilo Otoni juntamente com Itambacuri serão responsáveis pela produção de aproximadamente $92,11 \%$ dos resíduos sólidos conforme o cenário projetado.

Figura5- Porcentagem de produção de resíduos sólidos por município

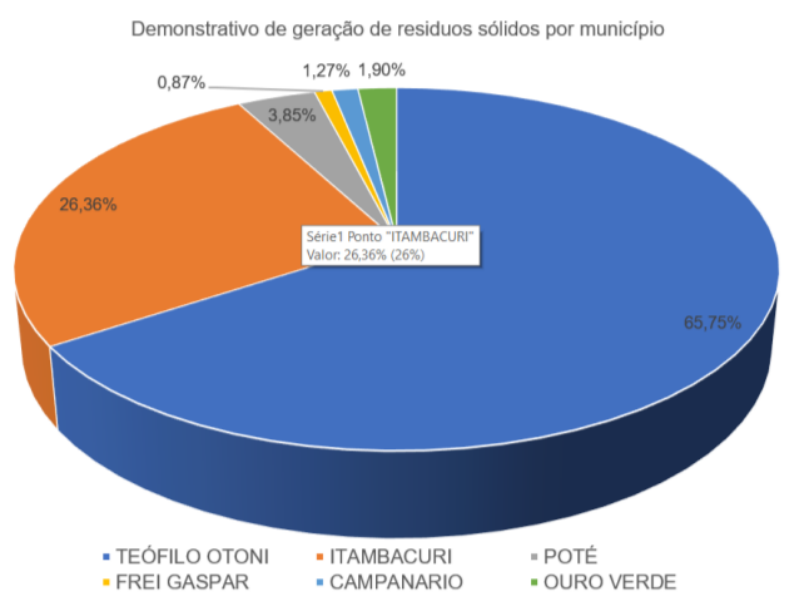

Fonte: (Dados da própria pesquisa, 2018)

Com base na análise da área de abrangência do aterro sanitário em função da produção de resíduos de cada município, definiu-se a área de implantação no município de Teófilo Otoni, por ser a maior produtora de resíduos. E para fins de logística procurou-se uma área próxima ao município de Itambacuri considerando a relevância de sua produção de resíduos.

Para definir o provável local da implantação do aterro sanitário, pesquisou-se áreas com superfície plana e com as dimensões desejadas. Nesse contexto entende-se que embora considere os a distância entre as cidades e a topografia como fatores relevantes não é possível afirmar que seja a área adequada, pois 
seriamnecessários detalhes legais, econômicos, técnicos e sociais, sobre a área escolhida.

Figura6- Delimitação da área do aterro sanitário

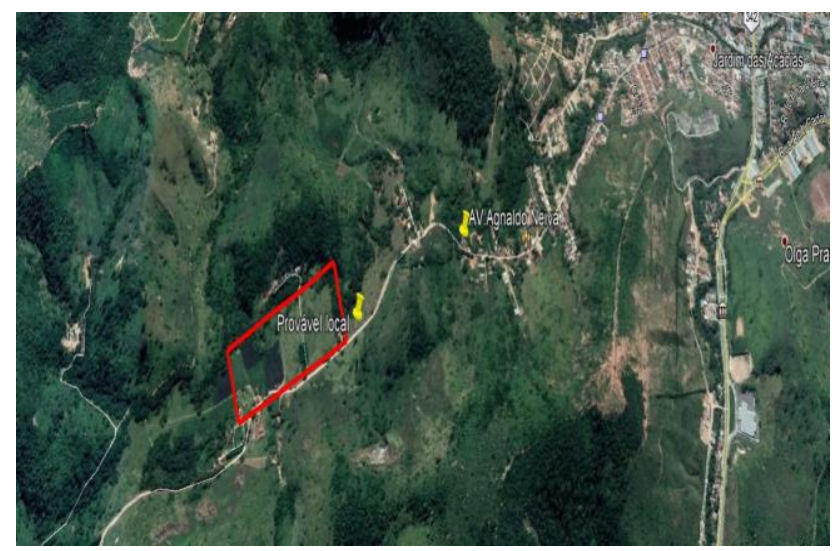

Fonte: (Google Earth, 2018)

A área analisada está situada a uma latitude $17^{\circ} 52^{\prime} 30.34^{\prime \prime}$ sul e a uma longitude 41³2'19.95" oeste. As distâncias dos municípios em relação à área delimitada são demonstradas na Figura a seguir:

Tabela6- Porcentagem de produção de resíduos sólidos por município

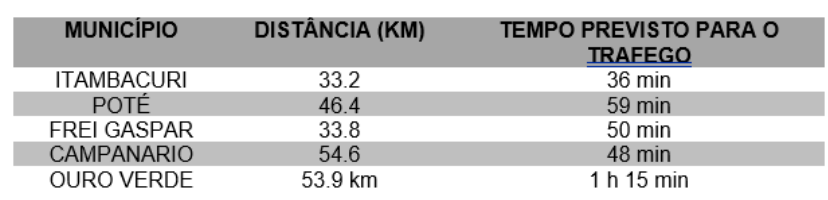

Fonte: (Dados da própria pesquisa, 2018)

A área escolhida possui uma boa via de acesso pela Av. Agnaldo Neiva que é interligada a BR 116, a via possui boas condições de infraestrutura urbana. O bairro Jardim das Acácias onde está localizada a área analisada não possui alto adensamento residencial, como pode se observar na Figura8. Portanto tende a ter um alto fluxo local baixo.

\subsection{Verificação de custos referentes à implantação do aterro sanitário consorciado}

Para o custo total do aterro sanitário foi adotado o valor de implantação calculado pela ABETRE (2017), para aterros modelo. O aterro dimensionado pela a ABETRE tem a capacidade diária de até 300 toneladas, portanto considerando ser 
maior do que a capacidade do aterro dimensionado, que tem a capacidade diária de 255 toneladas diárias, o cálculo foi readequado, tendo como referência o valor total calculado pela ABETREpara o custo do aterro por tonelada. Nesse contexto, utilizouse a sensibilidade do preço mínimo de $\mathrm{R} \$ 8,32$ por toneladas dia para implantação do aterro sanitário com base na análise da Fundação de Pesquisa Econômica (FIPE, 2017).

Portanto adequando as características do aterro sanitário em estudo que apresenta uma produção diária de resíduos sólidos de 255 toneladas, o custo total e dada pela formula abaixo:

$$
\begin{aligned}
& \mathrm{CT}=(\mathrm{SPT} \times \mathrm{CPD} \times 365 \times \text { útil }) \\
& \text { Onde } \\
& \mathrm{CT}=\text { Custo Total } \\
& \mathrm{SPT}=\text { Sensibilidade do Preço Mínimo } \\
& \mathrm{CPD}=\text { Capacidade diária } \\
& \mathrm{CT}=(8,32 \times 255 \times 365) \\
& \mathrm{CT}=\mathrm{R} \$ 774.887,73 \text { /ano }
\end{aligned}
$$

Como o aterro tem vida útil para 20 anos calculou-se o custo total da seguinte forma:

$$
\begin{aligned}
& C T=R \$ 774.887,73 * 20 \\
& C T=R \$ 15.497 .734,65
\end{aligned}
$$

Portanto calcula-se a taxa de resíduos sólidos conforme o método de Hortolani (2008) em que:

$\mathrm{T}=$ Ct anual

Quantidade de imóveis

Segundo a divisão de rendas imobiliárias Teófilo Otoni tem cadastrados no ano de 2018, aproximadamente 40.222 imóveis cadastrados em que anualmente é cobrada a taxa de resíduos sólidos, portanto para a taxa seria calculada desta forma:

$$
T=\underline{774.887,73}
$$


$\mathrm{T}=\mathrm{R} \$ 19,26$ imóvel /ano

\subsection{Investimentos para implantação do aterro sanitário}

No aterro sanitário consorciado serão depositadas aproximadamente tem $40.222,00$. Portanto, o benefício proveniente de um projeto de disposição final de resíduos sólidos urbanos, pela resulta em:

$\mathrm{B}=\mathrm{D} \times \mathrm{T}$

Onde:

$B=$ Beneficio

$\mathrm{D}=$ Média de quantidade de imóveis cadastrados

$\mathrm{T}=$ Taxa de resíduos sólidos

$B=40.222 \times 19,26$

$B=R \$ 774.887,73$

\subsection{Análise da viabilidade econômica para implantação do aterro sanitário consorciado}

A viabilidade econômica da implantação do aterro sanitário é dada pela relação custo e benefício supracitado no item 2.9 do presente estudo, formulada por Hortolani (2008), a equação tem a seguinte configuração:

$$
\mathrm{RBC}=\frac{P_{B}}{P_{C}}
$$

Para fins de aplicação para no presente estudo, ela foi reformulada a fim de obter de se adaptar ao presente estudo, onde:

$$
\mathrm{RBC}=\frac{P_{B}}{P_{C}}
$$

Onde:

$\mathrm{PB}=\mathrm{O}$ Benefício total

$\mathrm{PC}=$ Custo total

Portanto calculou-se:

$$
R B C=\frac{P B}{P U}=\frac{R \$ 774.887,73 \times 20}{R \$ 15.497 .734,65}
$$

$\mathrm{RBC}=1,00$

\section{CONCLUSÃO}


O aterro sanitário para atender os municípiosTeófilo Otoni, Poté, Ouro Verde, Itambacuri, Frei Gaspar e Campanário com uma vida útil de 20 anos, deve ter capacidade diária de 255 toneladas dia e capacidade máxima deaproximadamente1.858.950,28 toneladas de resíduos sólidos. O aterro sanitário dimensionado temuma área de aproximadamente 19,2 hectares. A decisão de implantar o aterro sanitário irá custar aproximadamente $R \$ 15.497 .734,65$ aos municípios consorciados.

Considerando a cobrança de uma taxa de resíduos sólido complementar anual de $\mathrm{R} \$ 19,26$ ano para os próximos 20 anos, para subsidiar a implantação do aterro sanitário, o valor do benefício simuladototalserá deR $\$ 15.497 .734,65$. Portanto a relação benefício/custo encontrada éiguala 1.Portando para a taxa de $R \$ 19,26$ o aterro sanitário torna-se inviável economicamente. Para definir a taxa complementar que viabilize o projeto tem-se

$$
\begin{aligned}
& R B C=P B / P C \geq 1,1 \\
& P B \geq 1,1 \times P C \\
& U \times \geq 1,1 \times P \\
& U \geq 1,01 \times 15.497 .734,65 \\
& U \geq R \$ 15.652 .711,99
\end{aligned}
$$

\section{Portanto}

$B=15.652 .711,99$ imóvel/ano

$$
\begin{aligned}
& 15.652 .711,99=\mathrm{D} \times \mathrm{T} \\
& 15.652 .711,99=40.222 \times(20 \text { anos }) \times T \\
& T=R \$ 19,45 \text { imóvel/ano }
\end{aligned}
$$

Para que o aterro sanitário fosse viável economicamente a taxa de resíduos complementar deveria ser de $\mathrm{R} \$ 19,45$ pelo o período de 20 anos, porém os municípios devem considerar a possibilidade de agregar benefícios como os ganhos ambientais, sociais e econômicos, que podem ser obtidos com a implantação do consórcio público intermunicipal de aterro sanitário, aumentando assim valor dos benefícios. Sobretudo não considerou as exigências legais, como a possibilidade de ocorrência de multas ambientais e a necessidade de se adequar à lei 12.305/2010, que exige a erradicação de lixões a céu aberto.

Conclui-se que embora seja inviável economicamente para municípios financiar o consórcio com os recursos próprios advindos da taxa de resíduos sólidos, 
os municípios de Teófilo Otoni, Poté, Ouro Verde, Itambacuri, Frei Gaspar e Campanário, devem considerar, subsídios através de fontes de recursos federaispara regularizar a situação em relação a disposição final dos resíduos sólidos por determinação da lei.

\section{REFERÊNCIAS}

ALBEPRE. Panorama Dos Resíduos Sólidos No Brasil 2011. São Paulo. 2011.

.ALMEIDA , I. N. (2015). RECUPERAÇÃO DE LIXÕES: Proposta de Metodologia de apoio á tomada de decisão. Trabalho Final de Curso apresentado ao Colegiado do Curso de Engenharia Sanitária e Ambiental da Universidade Federal de Juiz de Fora,, Juiz de Fora. Acesso em 16 de Dezembro de 2018, disponível em www.uff.br: http://www.ufjf.br/engsanitariaeambiental/files/2014/02/TCC_Israel_FINALIZADO.pdf

ARAÚJO, O. J. (2017). PRAC. Acesso em 16 de Dezembro de 2018, disponível em www.prac.com.br: https://www.prac.com.br/site/pt-BR/literaturas-3/pesquisa/o-que-e-aterro-sanitario.html

ASSOCIAÇÃO BRASILEIRA DE NORMAS TÉCNICAS. NBR 10004: Resíduos sólidos Classificação. Rio de Janeiro. 2004.

BARROS , J. A. (2014). A nova gestão dos resíduos sólidos urbanos no brasil: da reparação à prevenção. Dissertação apresentada ao Programa de PósGraduação, Pontifícia Universidade, Goiânia.

http://tede2.pucgoias.edu.br:8080/bitstream/tede/2681/1/JULIANO\%20DE\%20BARROS\%20ARAUJO. pdf

BATISTA, E. C. Escolha de uma área para disposição final dos resíduos sólidos urbanos e dimensionamento de um aterro sanitário para a cidade de campos dos Goytacazes/RS. Campos dos Goytakazes. 2005.

BORBA, W. F. Vunerabiliade á contaminação da água subterranea em uma área ocupada por um aterro sanitário- RS. Santa Maria. 2016.

BRASIL. Resolução CONAMA № 313, de 29 de outubro de 2002. Dispõe sobre o Inventário Nacional de Resíduos Sólidos Industriais, 5 agosto 1993. Disponivel em:

<http://www.siam.mg.gov.br/sla/download.pdf?idNorma=263>. Acesso em: 12 OUTUBRO 2018.

BRASIL, 2 AGOSTO 2010. Disponivel em: <http://www.planalto.gov.br/ccivil_03/_Ato20072010/2010/Lei/L12305.htm>. Acesso em: 12 Setembro 2018.

BRASIL. Lei no 12.305, de 2 de agosto de 2010. Institui a Política Nacional de Resíduos Sólidos, 2 Agosto 2010. Acesso em: 13 Setembro 2018.

Carlos , J. M., Melo , M. d., Costa, V. d., e Fadlo , W. C. (2012). CARACTERÍSTICAS E IMPACTOS AMBIENTAIS CAUSADOS PELOSRESIIDUOS SÓLIDOS: UMA VISÃO CONCEITUAL. Águas Subterrâneas.

.CONAMA. (2004). Altera a Resolução CONAMA no 307, de 5 de julho de 2002, incluindo o amianto na classe de resíduos perigosos

CONSTITUIÇÃO FEDERAL. (1998). Meio Ambiente. Brasília,DF. Acesso em 16 de Dezembro de 2018, disponível em http://www.senado.leg.br/atividade/const/con1988/con1988_06.12.2017/art_225_.asp

CONTI, D., E MARTINS , R. C. (Dezembro de 2015). Gestão de Resíduos Sólidos: Desafios e Oportunidades para a Cidade de São Paulo. (A. J. Guevara, Ed.) Journal on Innovation and 
Sustainability, 6(Arnoldo José de Hoyos Guevara), 77-96. Acesso em 05 de Dezembro de 2018, disponível em file:///C:/Users/barba/Downloads/26977-70652-1-SM\%20(3).pdf

D'ALMEIDA, L ; VILHENA M.. Lixo municipal: manual de gerenciamento integrado. São Paulo, 2000.

.DANTAS, J. (2012). Gestão dos Resíduos Sólidos para Municípios de Pequeno e Médio Porte à Luz da Política Nacional de Resíduos Sólidos. UNIVERSIDADE FEDERAL RURAL DO SEMIÁRIDO CAMPUS ANGICOS, ANGICOS. Acesso em 2018 de Outubro de 21, disponível em http://www2.ufersa.edu.br/portal/view/uploads/setores/232/TCC\%20\%20Jos\%C3\%A9\%20Humberto.pdf

FARINAS , G. A. (2006). O Gerenciamento Integrado de Resíduos Sólidos e a Reciclagem. Associação mineira de Defesa do meio Ambiente.

.FEAM. (2016). FEAM. Acesso em 2018 de Dezembro de 2018, disponível em http://www.feam.br: http://www.feam.br/noticias/1/581-feam-divulga-novos-dados-da-disposicao-deresiduos-solidos-urbanos-em-minas

.FIPE. (2017). Aspectos técnicos e econômico-financeiros da implantação, manutenção, operação e encerramento de aterros sanitários. São Paulo. Fonte: https://www.selur.com.br/wpcontent/uploads/2017/06/FIPE-RELAT\%C3\%93RIO-ASPECTOS-ECONOMICO-FINANCEIROSATERROS.pdf

GOMES , M. D., VENTURA, A., \& RODRIGUES, É. (Agosto de 2014). POLÍTICA NACIONAL DE RESÍDUOS SÓLIDOS (PNRS) - UMA INVESTIGAÇÃO DOS DESAFIOS E MECANISMO DE APOIO PARA IMPLEMENTAÇÃO EM TRÊS MUNICÍPIOS DO INTERIOR DE SÃO PAULO. Excelência em Gestão, 1-21. Acesso em 16 de Dezembro de 2018, disponível em http://www.inovarse.org/sites/default/files/T14_0430.pdf

GUIMARÃES, L. T. Utilização do Sistema de Informação Geográfica (SIG) para identificação de áreas potenciais para disposição de resíduos na Bacia do Paquequer, município de Teresópolis.

Dissertação (M.S.) Universidade Federal do Rio de Janeiro. Rio de Janeiro, 2000.

GODECKE, M. V.; HARB, R. N.; SGANDERLA, J. A. F. O consumismo e a geração de resíduos sólidos urbanos no brasil. Rev. Elet. em Gestão, Educação e Tecnologia Ambiental, 5 Setembro 2012. p. 1700-1712. Disponivel em: <http://web-resol.org/textos/6380-33840-2-pb-2.pdf >. Acesso em: 2018 Setembro 21.

GUIMARÃES, L. T.; Utilização do Sistema de Informação Geográfica (SIG) para identificação de áreas potenciais para disposição de resíduos na Bacia do Paquequer, município de Teresópolis. Rio de Janeiro, 2000. Dissertação (M.S.). Universidade Federal do Rio de Janeiro. Disponível em:

http://www.labgis.uerj.br/publicacoes/lucy/

.HAMADA, J. UNESP/FEB. Comunicação pessoal sobre o orçamento do aterro sanitário de Presidente Prudente. 2005.

.HAMADA, J. Concepção de Aterros Sanitários: Análise Crítica e Contribuições para seu Aprimoramento no Brasil. Tese de Livre Docência. UNESP/FEB. Bauru. 2003. 254p.

HELDER, R. 2006. Como fazer análise documental. Porto, Universidade de Algarve

HORTOLANI, P. S. R. Análise de viabilidade econômica de um aterro sanitário para cidade de pequeno porte. Faculdade de Engenharia de llha Solteira - UNESP. ILHA SOLTEIRA. 2008.

IBGE. (2017). Pesquisa de Informações Básicas Municipais. Acesso em 16 de Dezembro de 2018, disponível em IBGE: https://ww2.ibge.gov.br/home/estatistica/economia/perfilmunic/2015/default.shtm

KIRCHNER, J. B. A utilização da projeção populacional na elaboração de projetos de saneamento básico: estudo de caso, ljuí, rs. IJUí. ljuí. 2007. 
.LAKATOS, E. M.; MARCONI, M. A. Fundamentos metodologia científica. 4.ed. São Paulo: Atlas, 2001.

LUIZ, e. (2010). INTRODUÇÃO AO GERENCIAMENTO AMBIENTAL (1 ed.). Rio de Janeiro: Interciência.

MARCONI, LAKATOS. (2003). Fundamentos da metodologia cientifica. Atlas.

MALHOTRA. (2001). Pesquisa de marketing. Porto Alegre:: Bookman.

MATTAR, F. N. Pesquisa de marketing. 3.ed. São Paulo: Atlas, 2001.

MATTOS, GOMES,RIBEIRO , R. D. (2015). Resíduos sólidos no Brasil: conxtexto, lacunas e tendências. SCIELO, 20(4), 685-698. Acesso em 16 de Dezembro de 2018, disponível em http://www.scielo.br/pdf/esa/v20n4/1413-4152-esa-20-04-00685.pdf

McBEAN, E.A., ROVERS, F.A., FARQUHAR, G.J., Solid Waste Landfill Engineering and Design.Prentice Hall, Inc. p. 521, 1995

.MEDEIROS , D. A.; ALBERTO , J. F. A gestão de resíduos sólidos urbanos no brasil frente às questões da globalização. Revista Eletrônica do Prodema, Março 2011. 7-22. Disponivel em: <file:///C:/Users/barba/Downloads/118-1-258-1-10-20110331\%20(2).pdf>. Acesso em: 21 Setembro 2018.

MINISTÉRIO , CIDADES. (2013). SNIS - Série Histórica. Fonte: app3.cidades.gov.br: http://app3.cidades.gov.br/serieHistorica/

.MINISTÉRIO , CIDADES. SNIS - Série Histórica. app3.cidades.gov.br, 2015. Disponivel em: <http://app3.cidades.gov.br/serieHistorica/>.

MINISTÉRIO DO MEIO AMBIENTE. (2015). Registros de experiências de educação ambiental e comunicação desenvolvidas em Unidades de Conservação federais. Ministério do Meio Ambiente. Acesso em 16 de Dezembro de 2018, disponível em http://www.icmbio.gov.br/educacaoambiental/images/stories/acoes/Experiencias_EA_e_Comunicacao Atual.pdf

MORAES, José laécio de. Consórcios intermunicipais: alternativa para o manejo integrado dos resíduos sólidos na região centro-sul do Ceará. Dissertação (Mestrado). Universidade estadual paulista (UNESP). Rio Claro - SP 2013.

OLIVEIRA , R. N., E OTÁVIO , C. P. (2008). Modelo de estimativa dos custos em aterros sanitários para apoio no gerenciamento de resíduos sólidos urbanos. $1^{\circ}$ Congresso Internacional de Tecnologias para o Meio Ambiente , (pp. 1-8). Bento Gonçalves .

Penido, J. (2001). Manual de gerenciamento integrado de resíduos sólidos. Rio de Janeiro. Acesso em 17 de Dezembro de 2018, disponível em http://www.resol.com.br/cartilha4/manual.pdf

PEREIRA , S. S., LIRA , F. G., E RODRIGUES , A. A. (2013). SITUAÇÃO SOCIAL DAS CATADORAS E DOS CATADORES. Brasília. Acesso em 17 de Dezembro de 2018, disponível em http://www.ipea.gov.br/agencia/images/stories/PDFs/situacao_social/131219_relatorio_situacaosocial _mat_reciclavel_brasil.pdf

PEREIRA , A. V. (na disposição final). Redução de emissões. 2007: IBAM.

POLETO, C. (2010). Introdução ao gerenciameto ambiental. rio de janeiro: interciência.

PORTAL DOS RESIDUOS SÓLIDOS. (2013). portalresiduossolidos.com. Acesso em 16 de Dezembro de 2018, disponível em Portal dos Resíduos Sólidos:

https://portalresiduossolidos.com/aterro-sanitario/

RAFAEL MATTOS DEUS, R. A. (2015). Resíduos sólidos no Brasil : contexto, lacunas e tendências. SCIELO, 14. 
RIBEIRO , T. B. (2017). egov.ufsc.br. Acesso em 16 de Dezembro de 2018, disponível em http://egov.ufsc.br: http://egov.ufsc.br/portal/sites/default/files/anexos/26538-26540-1-PB.pdf

ROBERTO, RISSO, LUIZ, P. W. M. J. G. G. Agenda 21 e Governança. scielo, São Paulo, v. 26, p. 74, 2012. ISSN ISSN 0103-4014. Disponivel em:

<http://www.scielo.br/scielo.php?script=sci_arttext\&pid=S010340142012000100025.

RODRIGUES , G. S. (2017). CARACTERIZAÇÃO E DIMENSIONAMENTO DE ATERROS SANITÁRIOS PARA RESÍDUOS SÓLIDOS URBANOS NO BRASIL E NOS MUNICÍPIOS PAULISTAS. RELATÓRIO FINAL DE PROJETO DE INICIAÇÃO CIENTÍFICA - CNPq, São Paulo. Acesso em 16 de Dezembro de 2018, disponível emfile:///C:/Users/barba/OneDrive/Área\%20de\%20Trabalho/Pedro\%20Tcc/Artigos\%20utilizados/carac terizac3a7c3a3o-e-dimensionamento-de-ateero-sanitc3a1rio-1\%20(2).pdf

SANDRA TÉDDE SANTAELLA,Resíduos sólidos e a atual política AMBIENTAL BRASILEIRA. Fortaleza: LABOMAR, v. 7, 2014. ISBN 978-85-420-0326-0.

SANTOS, ; SOUZA , N. R. R. Cenário brasileiro da gestão dos resíduos sólidos urbanos e coleta seletiva. VI SINGEP, p. 14, 2017.

SILVA , C. F. (2012). PANORAMA DOS RESÍDUOS SÓLIDOS NO BRASIL. ALBREPE, SÃO PAULO.

SILVA, S. S. D.; SILVA, G. D. D. N. D.; DUARTE, G. R. Atendimento à legislação ambiental. Revista de Administração da Universidade Federal de Santa Maria, p. 100, 2016.

SNIS. Diagnóstico anual dos residuos sólidos. Sistema nacional sobre o saneamento, 2018.

Disponivel em: <http://www.snis.gov.br/diagnostico-residuos-solidos>.

TÉDDE. (2014). Resíduos Sólidos e atual politica ambiental brasileira (Vol. 7). Fortaleza, Ceará:

Habitat. Acesso em 16 de Dezembro de 2018, disponível em

http://www.repositoriobib.ufc.br/000011/00001121.pdf 